\title{
The evolving role of prophylactic use of tranexamic acid before cesarean section: balance between maternal benefits and unknown neonatal effects
}

\author{
Omar Viswanath*, Sushmitha Santhosh ${ }^{\dagger}$ and Howard Goldman ${ }^{\dagger}$
}

*Correspondence: viswanoy@gmail.com

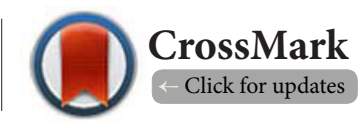

'These authors contributed equally to this work.

Department of Anesthesiology, Mount Sinai Medical Center, Miami Beach, Florida, USA.

\begin{abstract}
Tranexamic acid (TXA), an antifibrinolytic agent, has recently been investigated as a potentially useful drug for both prevention and treatment of Primary Postpartum Hemorrhage (PPH). This article highlights the continuing evolvement of this antifibrinolytic medication in the broad field of anesthesiology, and more specifically, obstetric anesthesiology, focusing on three important aspects of TXA administration: the continuing studies and assessment of the potential benefits of TXA administration to minimize PPH in both non high risk and high risk parturients, the possible adverse effects of TXA on the mother, and finally the unknown risks of the administration of TXA to the neonate. Although there is promise in the use of TXA for prevention and treatment of PPH, large, high quality randomized controlled trials are necessary on all three of these aspects before its widespread use can be recommended safely. Until that time, it is imperative that the anesthesiologist be well informed on this delicate balance of potential benefit of TXA to the mother versus potential and unknown risk to the mother and neonate.
\end{abstract}

Keywords: Perioperative complications, high risk obstetric parturients, primary postpartum hemorrhage, tranexamic acid, anesthetic issues and peri-operative care, preoperative evaluation and anesthesia risk, antifibrinolytics

\section{Introduction}

Primary postpartum hemorrhage (PPH) is a major cause of maternal mortality, accounting for close to one-quarter of all maternal deaths worldwide [1]. Until recently, uterotonic medications, specifically oxytocin, have been the only drugs shown to decrease PPH. Given that PPH remains a major cause of maternal mortality worldwide, there is a need for additional treatments and interventions. Tranexamic acid (TXA), an antifibrinolytic agent, has recently been investigated as a potentially useful drug for both prevention and treatment of PPH [1]. It has also been shown to reduce blood loss in elective surgery, cardiac surgery, and trauma. It has also been used to reduce menstrual blood loss [1]. TXA appears to be a promising drug for prevention and treatment of PPH after both vaginal and cesarean deliveries. However, as studies are currently ongoing to assess these benefits and unknown risks, the anesthesiologist must be aware of the evolving knowledge of TXA in the obstetric setting in order to maximize the beneficial effects on the mother while concurrently minimizing any potential deleterious effects on the neonate.

\section{Review}

Primary postpartum hemorrhage (PPH) is classically defined as blood loss of $\geq 500 \mathrm{~mL}$ for a vaginal delivery and $\geq 1000 \mathrm{~mL}$ for a cesarean delivery in the first 24 hours after delivery [2]. It is a major cause of maternal mortality and accounts for about one-quarter of all maternal deaths worldwide [1]. The leading cause of massive obstetric hemorrhage is uterine atony $[3,4]$, but obstetric complications such as placental abruption, placenta accreta, and amniotic fluid embolism may also precipitate obstetric hemorrhage, often times complicated by consumptive coagulopathy [4]. Risk factors for PPH include previous PPH, obesity, prolonged labor, multiple pregnancies, prior caesarean delivery, primiparity, polyhydramnios, and macrosomia [5].

The coagulation and fibrinolytic systems are believed to be in a state of dynamic balance that maintains an intact vascular

(c) 2015 Viswanath et al; licensee Herbert Publications Ltd. This is an Open Access article distributed under the terms of Creative Commons Attribution License (http://creativecommons.org/licenses/by/3.0). This permits unrestricted use, distribution, and reproduction in any medium, provided the original work is properly cited. 
system [6]. During delivery, when the placenta separates from the uterine wall, physiologic and hemostatic changes occur sequentially to reduce bleeding: strong myometrial contractions, increased platelet activity, massive release of coagulation factors and consequently a parallel increase in fibrinolytic activity [7]. Tranexamic acid (TXA) is a potent antifibrinolytic agent that exerts its effects by blocking the link between plasminogen kringle 5 and lysine site of the fibrin heavy chain at one of the sites where antiplasmin and thrombin-activatable fibrinolysis inhibitor (TAFI) have their potential action. Thus, depending on the dose and the condition of the tertiary complex elements of the patient (tPANative Fibrin-plasminogen) and the secretion of the natural antifibrinolytic (antiplasmin depending on the liver function and TAFI depending on the thrombin secretion), tranexamic acid can supply a deficient natural antifibrinolysis or be competitive with it. This is one of the challenges of future trials to determine the optimal dose and the best timing of administration in the course of the fibrinolytic process.

The majority of the larger studies regarding TXA have been focused on broader categories of surgical patients. The Clinical Randomisation of an Antifibrinolytic in Significant Haemorrhage-2 (CRASH-2) trial randomized more than 20,000 adult trauma patients to receive empiric tranexamic acid within 8 hours of injury or placebo. The study not only found a significant decrease in all-cause mortality $(14.5 \%$ vs $16 \%$, relative risk: $0.91,95 \% \mathrm{Cl}: 0.85-0.97, P=0.0035)$ as well as mortality due to hemorrhage ( $4.9 \%$ vs $5.7 \%$ ) in the tranexamic acid group, but importantly showed no significant increase in thromboembolic complications in subjects receiving tranexamic acid [8].

With regards to studies specifically addressing TXA effects on prevention of PPH, a recent article by L. Sentilhes et al., published in the British Journal of Anesthesia found 10 published Randomized Controlled Trials (RCT) evaluating the efficacy of TXA in preventing PPH after elective non haemorrhagic caesarean delivery [1]. Their characteristics are summarized in a table created by $L$. Sentilhes and can be seen here in Table 1 . The 10 published RCTs that have assessed the effects of TXA in preventing PPH during caesarean deliveries showed a significant reduction in blood loss in patients who received TXA and no increase in the incidence of adverse events [1] (Table 1). Although these results are promising and support the use of TXA, it must be noted that majority of these RCTs included small sample sizes with inadequate power to fully assess the risk of adverse effects.

Of these 10 RCTs, one in particular, Goswami et al., demonstrated a decrease in estimated blood loss when tranexamic acid was used prophylactically before elective caesarean section in anemic patients [9]. In the study, it was found that even minimal blood loss reduction probably helped to avoid packed red blood cell transfusion in the two TXA groups compared to the placebo group [9]. The choice of this particular population of high risk obstetric parturients is of high importance. Even if the outcome of the currenty ongoing clinical trials reveals there is minimal benefit on mortality to using TXA on non high-risk patients, this particular study highlights the need for more focused studies on the targeted use of TXA in treating high risk obstetric patients. High risk obstetric patients specifically include the populations of anemic patients as well as mothers with high risk obstetric conditions including placental abruptions or abnormal placentation, including placenta accreta, increta, and percreta. Even minimal blood loss in these patients can have a far more devastating outcome on the patient and even a minimal reduction in bleeding can potentially be of great benefit.

There are very few studies specifically addressing the adverse effects or even the possible risks of TXA. A recent study by Kratzer et al., concluded that TXA administered at clinically relevant concentrations increases the propagation of neuronal excitation in the basolateral nucleus of the amygdala. The observed enhancement of neuronal excitation arises from reduced synaptic inhibition rather than from increased neuronal excitability [10]. TXA impairs neuronal inhibition by a postsynaptic antagonism against $\mathrm{GABA}_{A}$ receptors. In contrast, TXA does not affect the excitatory glutamatergic synaptic transmission. Because inhibitors of $\mathrm{GABA}_{A}$ receptors are known to act in a proconvulsant manner, this mechanism of action may explain the increased incidence of seizures in patients treated with TXA [10]. This study elucidates a potential mechanism for the neuronal excitation and subsequent seizures that have been seen with TXA administration.

Given the sparsity of studies of maternal adverse effects with TXA, it should not be surprising that there are even fewer assessing the potential risks to the neonate. A recent study by Yee et al., found the effective concentration of TXA in neonatal plasma (in vitro) that inhibits fibrinolysis is far lower than the concentration needed in adults [11]. These two aforementioned studies speak for caution regarding neonatal exposure: there is a potential mechanism for seizures, and in addition the neonate may be more sensitive to low drug levels. These studies point to the need for further studies to be done asssessing the serum levels associated with neonatal seizures. As a result, this places even more importance on the timing of TXA administration. Until that information is obtained, it may be imperitive to continue suggesting that the drug be held until the cord is clamped. Most of the RCTs that have been completed at this time have involved the administration of the TXA well before the cord is clamped. Neonatal exposure will occur when TXA is given before the cord is clamped, as TXA is known to cross the placenta [12].

However, the unknown potential neonatal effect on a predelivery administration of TXA could have more potential clarity given the results of a very recent study by Wesley et al., on the pharmacokinetics of TXA in neonatal cardiac surgerywith cardiopulmonary bypass [13]. This study was the first population pharmacokinetic analysis of TXA in neonates and young infants undergoing cardiac surgery. The most 
Viswanath et al. Journal of Anesthesiology \& Clinical Science 2015,

Table 1. Characteristics of the randomized controlled trials that have assessed tranexamic acid for the prevention of postpartum hemorrhage after cesarean deliveries.

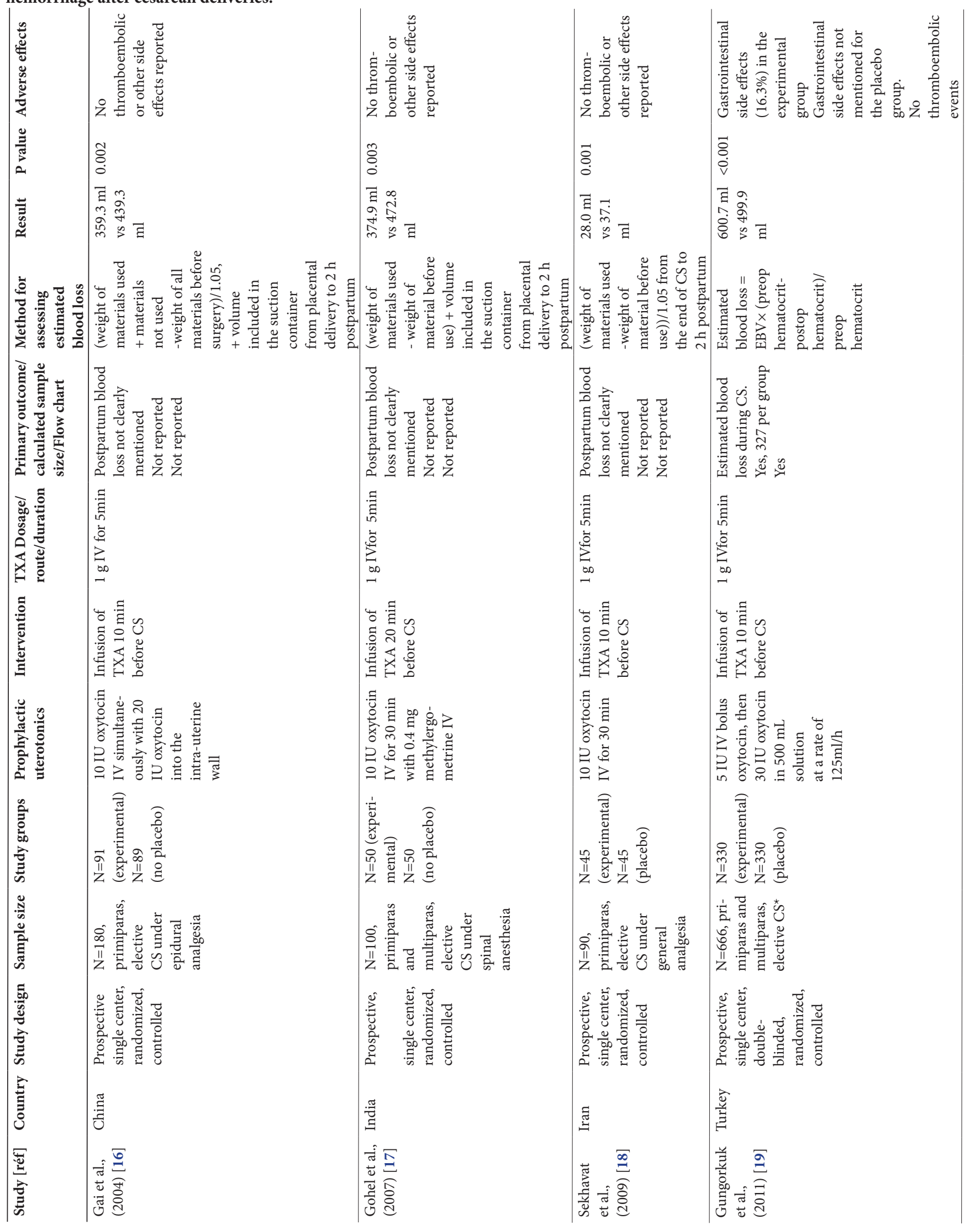




\section{Continuation of Table 1}

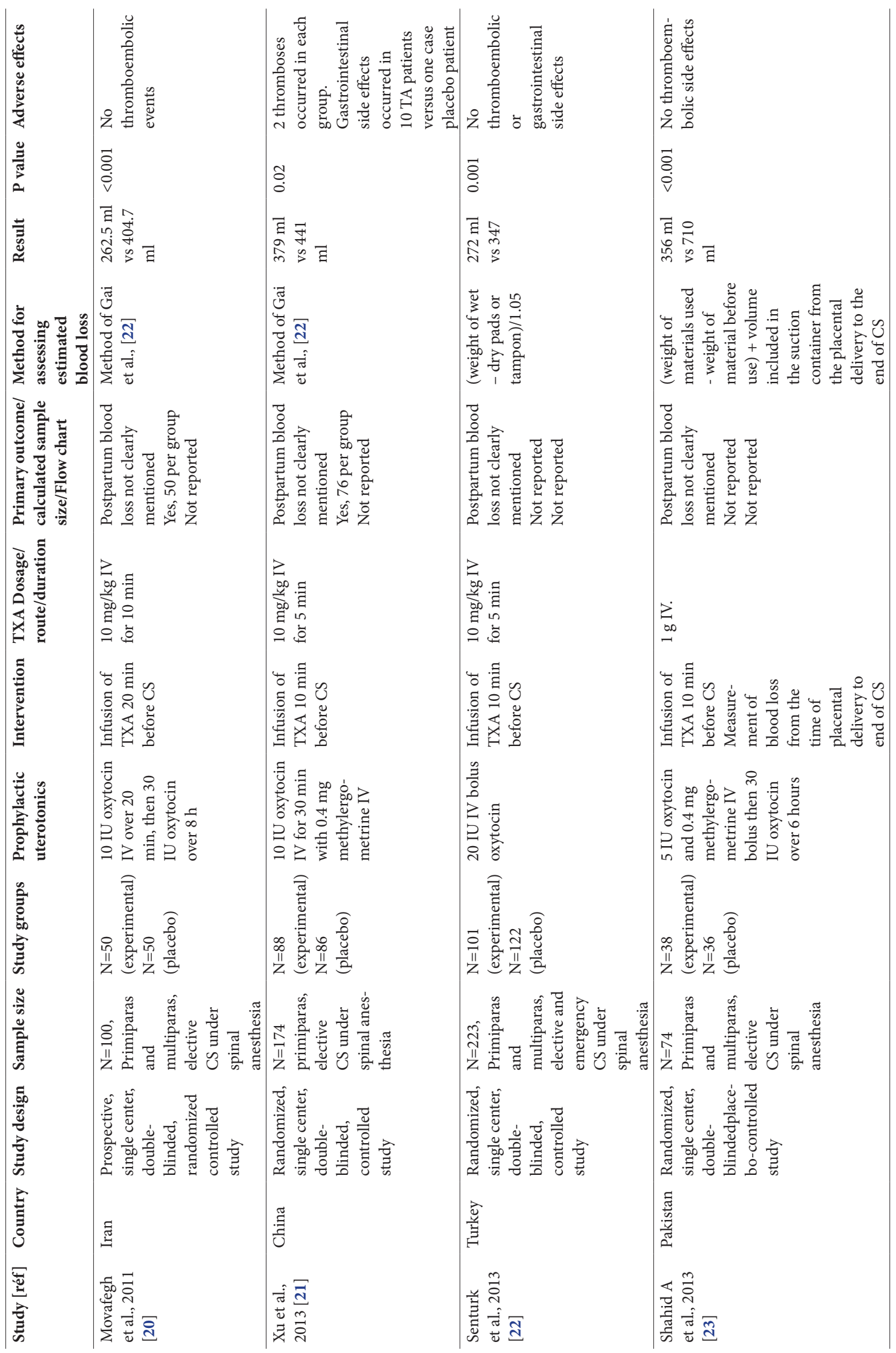




\section{Continuation of Table 1}

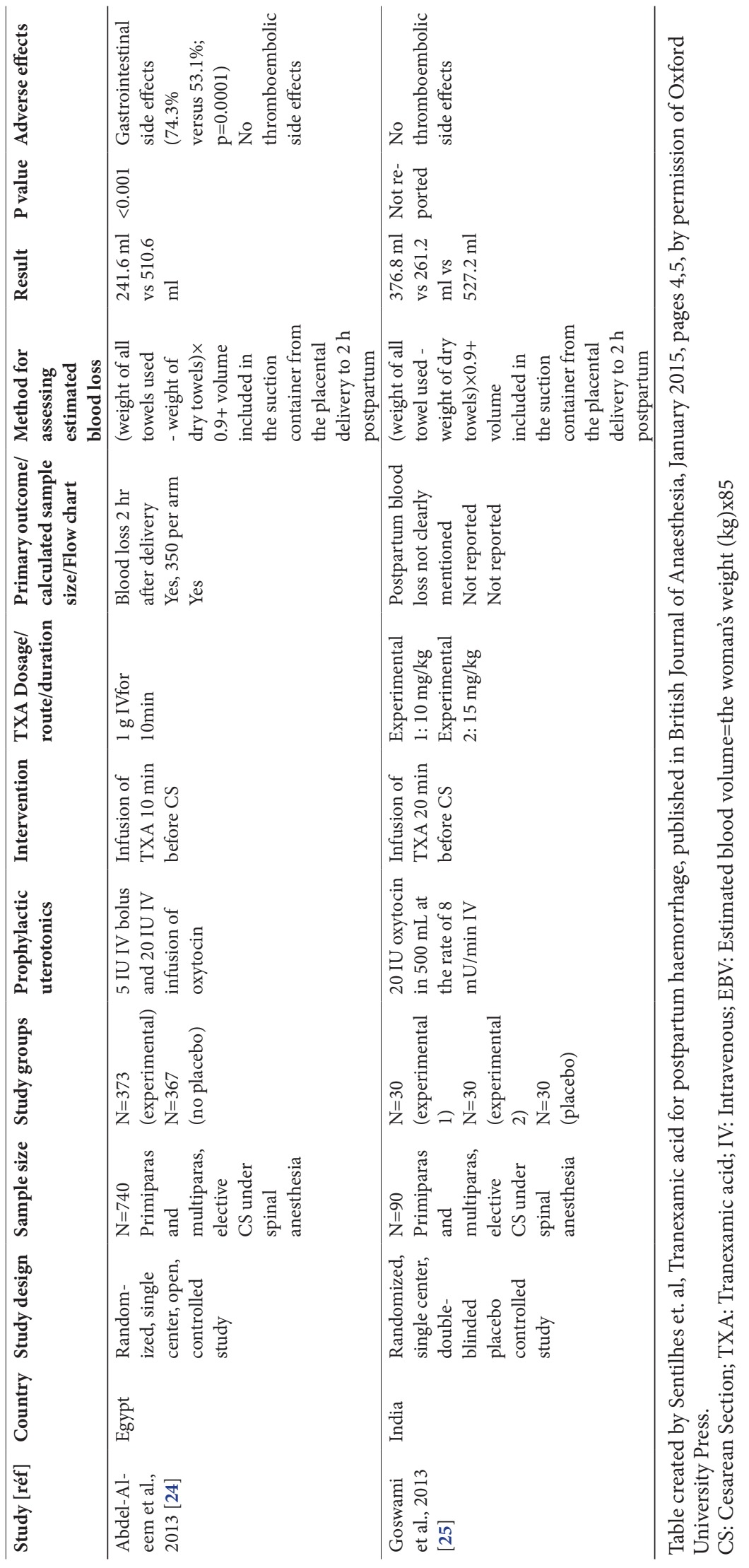


significant finding of their analysis was the need for different and generally reduced dosing regimens from those that are commonly used at this time. Additional findings include the importance of developmental changes during the first year of life leading to very different dosing requirements in newborns when compared with children over 12 months old. The dosing schedules found as a result of their study allow clinicians to target specific plasma concentrations in children of different ages. Their study also highlights that a single dose schedule used across all age ranges to achieve a desired plasma TXA concentration is unlikely to be effective [13].

Alternatively, a study by O. Gilad et al., evaluated the outcome of infants exposed to tranexamic acid during lactation. The results of their study found no increase in adverse longterm outcomes in infants exposed through breastfeeding to tranexamic acid. Their data, in conjunction with previous estimates of very low drug exposure, support continuation of breastfeeding in women treated with tranexamic acid [14]. This study compared to the prior two mentioned studies highlight the lack of concrete evidence of adverse effects of TXA on the neonate.

\section{Conclusions}

Although there is promise in the use of TXA for prevention and treatment of PPH, large, high quality RCTs are necessary before widespread usage can be supported and considered safe for administration. Of note, The World Maternal Antifibrinolytic Trial (WOMAN) trial, which is a large, international randomized placebo controlled study, is currently ongoing at this time to compare the impact of a $1 \mathrm{~g}$ dose of TXA at the onset of post-partum bleeding on mortality [15]. The results of this study should provide more evidence about the potential benefits of TXA to the mother.

List of abbreviations

PPH: Primary Postpartum Hemorrhage

TXA:Tranexamic Acid

RCT: Randomized Controlled Trials

CRASH-2: Clinical Randomisation of an Antifibrinolytic in Significant Haemorrhage-2

TAFI:Thrombin-Activatable Fibrinolysis Inhibitor

\section{Competing interests}

The authors declare that they have no competing interests.

Authors' contributions

\begin{tabular}{|l|c|c|c|}
\hline Authors' contributions & OV & SS & HG \\
\hline Research concept and design & $\checkmark$ & $\checkmark$ & $\checkmark$ \\
\hline Collection and/or assembly of data & $\checkmark$ & $\checkmark$ & $\checkmark$ \\
\hline Data analysis and interpretation & $\checkmark$ & $\checkmark$ & $\checkmark$ \\
\hline Writing the article & $\checkmark$ & -- & -- \\
\hline Critical revision of the article & $\checkmark$ & -- & $\checkmark$ \\
\hline Final approval of article & $\checkmark$ & $\checkmark$ & $\checkmark$ \\
\hline
\end{tabular}

Publication history

EIC: D. John Doyle, Case Western Reserve University, USA.

Received: 26-Aug-2015 Final Revised: 09-Oct-2015

Accepted: 15-Oct-2015 Published: 21-Oct-2015

\section{References}

1. Sentilhes L, Lasocki S, Ducloy-Bouthors AS, Deruelle P, Dreyfus M, Perrotin F, Goffinet F and Deneux-Tharaux C. Tranexamic acid for the prevention and treatment of postpartum haemorrhage. Br J Anaesth. 2015; 114:576-87. | Article | PubMed

2. World Health Organization. Managing complications in pregnancy and childbirth. Geneva, Switzerland: World Health Organization. 2000. I Pdf

3. James $A H, M c L i n t o c k C$ and Lockhart E. Postpartum hemorrhage: when uterotonics and sutures fail. Am J Hematol. 2012; 87 Suppl 1:S16-22. | Article I PubMed

4. Mhyre JM, Shilkrut A, Kuklina EV, Callaghan WM, Creanga AA, Kaminsky $\mathrm{S}$ and Bateman $\mathrm{BT}$. Massive blood transfusion during hospitalization for delivery in New York State, 1998-2007. Obstet Gynecol. 2013; 122:128894. | Article | PubMed Abstract | PubMed Full Text

5. Kramer MS, Berg C, Abenhaim H, Dahhou M, Rouleau J, Mehrabadi A and Joseph KS. Incidence, risk factors, and temporal trends in severe postpartum hemorrhage. Am J Obstet Gynecol. 2013; 209:449 e1-7. | Article | PubMed

6. Novikova N and Hofmeyr GJ. Tranexamic acid for preventing postpartum haemorrhage. Cochrane Database Syst Rev. 2010; CD007872. | Article | PubMed

7. Hellgren M. Hemostasis during normal pregnancy and puerperium. Semin Thromb Hemost. 2003; 29:125-30. | Article | PubMed

8. Shakur H, Roberts I, Bautista R, Caballero J, Coats T, Dewan Y, El-Sayed H, Gogichaishvili T, Gupta S and Herrera J et al. Effects of tranexamic acid on death, vascular occlusive events, and blood transfusion in trauma patients with significant haemorrhage (CRASH-2): a randomised, placebo-controlled trial. Lancet. 2010; 376:23-32. | Article | PubMed

9. Goswami U, Sarangi S, Gupta S and Babbar S. Comparative evaluation of two doses of tranexamic acid used prophylactically in anemic parturients for lower segment cesarean section: A double-blind randomized case control prospective trial. Saudi J Anaesth. 2013; 7:42731. | Article | PubMed Abstract | PubMed Full Text

10. Kratzer S, Irl H, Mattusch C, Burge M, Kurz J, Kochs E, Eder M, Rammes $\mathrm{G}$ and Haseneder $\mathrm{R}$. Tranexamic acid impairs gamma-aminobutyric acid receptor type A-mediated synaptic transmission in the murine amygdala: a potential mechanism for drug-induced seizures? Anesthesiology. 2014; 120:639-49. | Article | PubMed

11. Yee BE, Wissler RN, Zanghi CN, Feng $C$ and Eaton MP. The effective concentration of tranexamic acid for inhibition of fibrinolysis in neonatal plasma in vitro. Anesth Analg. 2013; 117:767-72. | Article | PubMed

12. Walzman M and Bonnar J. Effects of tranexamic acid on the coagulation and fibrinolytic systems in pregnancy complicated by placental bleeding. Arch Toxicol Suppl. 1982; 5:214-20. | Article | PubMed

13. Wesley MC, Pereira LM, Scharp LA, Emani SM, McGowan FX, Jr. and DiNardo JA. Pharmacokinetics of tranexamic acid in neonates, infants, and children undergoing cardiac surgery with cardiopulmonary bypass. Anesthesiology. 2015; 122:746-58. | Article | PubMed

14. Gilad O, Merlob P, Stahl B and Klinger G. Outcome following tranexamic acid exposure during breastfeeding. Breastfeed Med. 2014; 9:407-10. | Article | PubMed

15. Shakur H, Elbourne D, Gulmezoglu M, Alfirevic Z, Ronsmans C, Allen E and Roberts I. The WOMAN Trial (World Maternal Antifibrinolytic Trial): tranexamic acid for the treatment of postpartum haemorrhage: an international randomised, double blind placebo controlled trial. Trials. 2010; 11:40. | Article | PubMed Abstract | PubMed Full Text

16. Gai MY, Wu LF, Su QF and Tatsumoto K. Clinical observation of blood loss reduced by tranexamic acid during and after caesarian section: a multi-center, randomized trial. Eur J Obstet Gynecol Reprod Biol. 2004; 112:154-7. | Article | PubMed

17. Gohel M, Patel P, Gupta A and Desai P. Efficacy of tranexamic acid in decreasing blood loss during and after caesarean section: a randomized case controlled prospective study. J ObstetGynecol India. 2007; 57:22730.

18. Sekhavat L, Tabatabaii A, Dalili M, Farajkhoda T and Tafti AD. Efficacy of 
Viswanath et al. Journal of Anesthesiology \& Clinical Science 2015, http://www.hoajonline.com/journals/pdf/2049-9752-4-4.pdf

tranexamic acid in reducing blood loss after cesarean section. J Matern Fetal Neonatal Med. 2009; 22:72-5. | Article I PubMed

19. Gungorduk K, Yildirim G, Asicioglu O, Gungorduk OC, Sudolmus S and Ark C. Efficacy of intravenous tranexamic acid in reducing blood loss after elective cesarean section: a prospective, randomized, double-blind, placebo-controlled study. Am J Perinatol. 2011; 28:233-40. | Article | PubMed

20. Movafegh A, Eslamian L and Dorabadi A. Effect of intravenous tranexamic acid administration on blood loss during and after cesarean delivery. Int J Gynaecol Obstet. 2011; 115:224-6. I Article I PubMed

21. Xu J, Gao W and Ju Y. Tranexamic acid for the prevention of postpartum hemorrhage after cesarean section: a double-blind randomization trial. Arch Gynecol Obstet. 2013; 287:463-8. I Article I PubMed

22. Senturk MB, Cakmak Y, Yildiz G and Yildiz P. Tranexamic acid for cesarean section: a double-blind, placebo-controlled, randomized clinical trial. Arch Gynecol Obstet. 2013; 287:641-5. | Article I PubMed

23. Shahid $A$ and Khan A. Tranexamic acid in decreasing blood loss during and after caesarean section. J Coll Physicians Surg Pak. 2013; 23:459-62. I PubMed

24. Abdel-Aleem $\mathrm{H}$, Alhusaini TK, Abdel-Aleem MA, Menoufy $M$ and Gulmezoglu AM. Effectiveness of tranexamic acid on blood loss in patients undergoing elective cesarean section: randomized clinical trial. J Matern Fetal Neonatal Med. 2013; 26:1705-9. I Article I PubMed

25. Goswami U, Sarangi S, Gupta S and Babbar S. Comparative evaluation of two doses of tranexamic acid used prophylactically in anemic parturients for lower segment cesarean section: A double-blind randomized case control prospective trial. Saudi J Anaesth. 2013; 7:42731. | Article | PubMed Abstract | PubMed Full Text

\section{Citation:}

Viswanath O, Santhosh S and Goldman H. The evolving role of prophylactic use of tranexamic acid before cesarean section: balance between maternal benefits and unknown neonatal effects. J Anesthesiol Clin Sci. 2015; 4:4. http://dx.doi.org/10.7243/2049-9752-4-4 